\title{
Da Seguridade Social à intersetorialidade: reflexões sobre a integração das políticas sociais no Brasil
}

\author{
Giselle Lavinas Monnerat \\ Universidade do Estado do Rio de Janeiro (UERJ)
}

\author{
Rosimary Gonçalves de Souza \\ Universidade do Estado do Rio de Janeiro (UERJ)
}

Da Seguridade Social à intersetorialidade: reflexões sobre a integração das políticas sociais no Brasil

Resumo: Neste artigo reflete-se sobre os dilemas da integração das políticas sociais no Brasil desde a inscrição da Seguridade Social na Carta Constitucional de 1988 até a tematização mais recente acerca da intersetorialidade. Constrói-se a análise, sobretudo, a partir das trajetórias das políticas de saúde e assistência social, haja vista que os legados institucionais e a história de formação dessas áreas fornecem uma base de argumentação fecunda para o estudo aqui proposto. Demonstra-se que o processo de implementação da Seguridade Social esbarra em obstáculos de ordem política e econômica que dificultam a promessa integradora proposta. Ademais, observa-se que o modelo descentralizado, sob o qual operam as políticas sociais, em especial as de saúde e assistência social, recoloca a necessidade de sinergia intersetorial para enfrentar a complexidade dos problemas sociais. Por fim, busca-se destacar os principais desafios à integração das políticas sociais, sinalizando tratar-se de tarefa nada trivial.

Palavras-chave: Seguridade Social. Intersetorialidade. Saúde. Assistência social.

From Social Security to "Intersectoriality": Reflections on the Integration of Social Policies in Brazil Abstract: This article reflects on the dilemmas of integration of social policies in Brazil since the inscription of Social Security in the country's constitution of 1988 until the most recent theories on "intersectorality." The analysis is built above all on the trajectories of health care and social assistance policies, considering that the institutional legacies and the history of formation of these fields provide a base for fertile debate for this study. It demonstrates that the implementation of Social Security confronts political and economic obstacles that hamper the integrated promise proposed. In addition, it observes that the decentralized model from which social policies operate, in particular those for healthcare and social assistance, emphasizes the need for an intersectorial synergy to confront the complexity of social problems. Finally, it seeks to highlight the principal challenges to the integration of social policies, indicating that this is not a trivial task.

Key words: Social Security. Intersectoriality. Healthcare. Social assistance. 


\section{Introdução}

Este artigo objetiva discutir os principais dilemas que permeiam a implementação da Seguridade Social no Brasil, tomando como foco as trajetórias recentes das políticas de saúde e assistência social. Partese do entendimento de que, se por um lado, a Seguridade Social, tal como preconizado na Carta de 1988 (BRASIL, 2002), esbarra em viscerais obstáculos de ordem política e econômica para sua implementação, por outro, o modelo descentralizado, sob o qual passa a operar o sistema de proteção social, recoloca a questão da integração das políticas sociais a partir do esteio dos problemas enfrentados no contexto do que se convencionou chamar a "ponta do sistema". Assim, ainda que "recalcado", o problema da necessidade da integração retorna, uma vez que as áreas de política social que mais avançaram na direção de um novo arcabouço político-institucional (como o caso da saúde) se deparam hoje com limites estruturais da sociedade brasileira que necessitam de enfrentamento intersetorial, através da conformação de uma rede de proteção social.

Neste trabalho, diferentemente das áreas de saúde e assistência social, a abordagem está menos focada na Previdência Social, outro membro do tripé da Seguridade Social. Isto se justifica porque essa área se caracteriza por uma trajetória técnica e política bastante hermética, situação que até então não favoreceu a disseminação de propostas de mudanças, principalmente aquelas que dizem respeito à integração de ações entre diversas áreas de políticas. Se o princípio constitucional da descentralização não se coloca para a Previdência Social, a lógica intersetorial ainda parece estranha ao contexto desta arena política. Decerto, o status institucional da previdência faz com que as propostas relativas à integração com outras áreas setoriais tenham enorme dificuldade de penetração no âmbito dessa política.

A semântica inscrita no conceito de seguridade encerra a noção de proteção social do indivíduo e sua inclusão no rol de direitos providos pelo Estado, independentemente da sua inserção ou não na esfera do trabalho. Já o conceito de intersetorialidade se volta para a construção de interfaces entre setores e instituições governamentais (e não governamentais), visando o enfrentamento de problemas sociais complexos que ultrapassem a alçada de um só setor de governo ou área de política pública. Sendo assim, em ambas as concepções está presente, para sua consecução, o imperativo da integração entre as políticas, uma vez que tanto a Seguridade Social quanto a intersetorialidade se confrontam e devem responder à complexidade das demandas sociais contemporâneas. É no esforço de problematizar tais questões que reside o argumento central da análise aqui empreendida.

\section{Seguridade Social: da promessa de integração para além do vínculo contributivo aos pontos de inflexão marcantes de sua trajetória}

Como resultado do movimento de redemocratização do país, a Constituição Federal de 1988 (BRASIL, 2002), ao menos do ponto de vista normativo, ultrapassa a perspectiva de seguro social e inaugura a concepção de seguridade social. Esta é entendida como "um conjunto integrado de ações de iniciativa dos poderes públicos e da sociedade, destinadas a assegurar os direitos relativos à saúde, à previdência e à assistência social" (BRASIL, 2002, art. 194). A inclusão da previdência, da saúde e da assistência como integrantes da Seguridade Social introduziu a noção de direitos sociais universais como parte da condição de cidadania, antes restrita apenas aos beneficiários da Previdência Social.

A incorporação da noção de seguridade no Brasil implicou em um redimensionamento significativo das três políticas que a integram. No caso da saúde, o reconhecimento de que "a saúde é direito de todos e um dever do Estado" (BRASIL, 2002, art. 196) marcou uma mudança significativa com o modelo securitário representado pela medicina previdenciária, ampliando, assim, a própria concepção de direito à saúde. $\mathrm{Na}$ assistência social, é preciso reconhecer que, pela primeira vez, esta adquiriu o estatuto de política pública, entendida como área de intervenção do Estado, o que abriu possibilidades de rompimento com o legado assistencialista. E mesmo na Previdência Social, na qual se mantém a lógica contributiva que requer uma base atuarial para garantir sua sustentabilidade, verificou-se o afrouxamento do vínculo contributivo como princípio estruturante do sistema, legitimando programas de transferência de renda do porte da aposentadoria rural (FLEURY, 2006; VIANNA, 2001; MONNERAT; SENNA, 2007).

Entretanto, há consenso na literatura especializada na avaliação de que a Seguridade Social, tal como inscrita na Constituição de 1988, não foi ainda, de fato, implementada (FLEURY, 2006; VIANNA, 2001).

Em primeiro lugar, não se pode esquecer que a definição da legislação infraconstitucional aconteceu em conjuntura política e econômica bastante adver$\mathrm{sa}^{1}$. Deste modo, é possível dizer que a maior ou menor correspondência das leis orgânicas das diferentes arenas setoriais (saúde, assistência social e previdência) aos dispositivos constitucionais está relacionada à capacidade política, organizativa e de resistência dos atores envolvidos com essas políticas (MONNERAT; SENNA, 2007). Vianna $(1998,2001)$ argumenta que este conjunto de leis sedimentou caminhos diversos para as áreas envolvidas na Seguridade Social e, por conseguinte, tornou mais difícil a articulação do sistema de proteção social tal como prescrito na Constituição. 
Em segundo lugar, no que diz respeito ao financiamento da seguridade, foi prevista uma diversidade de fontes orçamentárias, visando imprimir um caráter mais redistributivo, mas na verdade não se conseguiu garantir que os recursos financeiros definidos constitucionalmente fossem a ela destinados. O período que segue a aprovação da Constituição é caracterizado por acirradas disputas entre os ministérios das áreas sociais e o Ministério da Fazenda. Este último, por sua vez, passa a realizar reiterados contingenciamentos ${ }^{2}$ de verbas destinadas às políticas sociais (VIANNA, 2005).

A forte concorrência entre as áreas de política que deveriam compor a Seguridade Social também contribuiu para o fracasso de sua implementação. Como consequência disso, ocorre a especialização das fontes de financiamento da seguridade por área de política social ${ }^{3}$, o que acaba de vez com a pretensão constitucional de se criar um orçamento único, cuja gestão se daria através de um ministério próprio. Com efeito, não houve por parte das três áreas envolvidas nenhum tipo de mobilização para lutar pelo orçamento unificado e tampouco pelo referido ministério, tal como previsto na Constituição (MONNERAT; SENNA, 2007). Esta postura impediu a formação de uma dada identidade da área social através da conformação do sistema de seguridade social e, em última instância, perdeu-se, sobretudo, a oportunidade de reforçar o debate em favor da integração entre política social e política econômica no país.

Em terceiro lugar, sem desconsiderar a conjuntura desfavorável em que se processou a implantação das mudanças constitucionais, é imprescindível assinalar que as trajetórias institucionais e o legado técnico e político das áreas de política social (saúde, assistência e previdência) exerceram influência direta sobre os caminhos tortuosos em direção à integração das áreas sociais.

Para Fleury (2006), o setor saúde assumiu posição ambígua e até mesmo divergente em relação à seguridade, temendo que a criação de um Ministério Único da Seguridade Social provocasse perda de identidade e especificidade na construção do Sistema Único de Saúde (SUS) (MONNERAT; SENNA, 2007).

Do ponto de vista da assistência social, observase que a fragilidade institucional e o viés clientelista, historicamente predominante, constituíram relevantes obstáculos à mobilização desta arena setorial.

Quanto à Previdência Social, o comportamento contrário à seguridade pode ser justificado por sua tradição de insulamento burocrático e forte caráter de centralização de decisão e gestão. Ademais, tem recursos garantidos através da arrecadação de contribuições sociais (VIANNA, 1998; MONNERAT; SENNA, 2007).

Verifica-se, então, que o abandono da ideia de seguridade social e a consequente desarticulação da área social têm repercussões negativas na condução da política social que persistem na atualidade.

A primeira delas diz respeito ao constante contingenciamento de recursos para o campo social que poderia ter sido minimizado não fosse a ausência de cooperação entre as três áreas envolvidas na Seguridade Social. Da mesma forma, como segunda repercussão, a não adoção da perspectiva sistêmica, traduzida na desarticulação entre saúde, assistência social e previdência, obstaculizou o desenvolvimento de uma cultura do diálogo e da promoção de ações intersetoriais no campo das políticas sociais, com consequências marcantes no contexto atual.

De fato, o abandono da perspectiva de integração da política social e o simultâneo reforço da competitividade entre setores sociais reiteraram a fragilidade no enfrentamento da fragmentação dos programas e ações nessa área, no país. Por tudo isso, dizse que a noção de seguridade social contém valores políticos que precisam ser resgatados de modo a rever os descaminhos da reforma até aqui empreendida(FLEURY, 2006).

Não obstante as questões antes descritas, buscase analisar como, na atualidade, a necessidade da interseção entre as políticas sociais permanece presente como mecanismo essencial à potencialização das ações no campo social. Toma-se como foco central de análise as inflexões nas políticas de saúde e de assistência social, haja vista que a Previdência Social, embora parte integrante da tríade da Seguridade Social, não tem evidenciado em sua trajetória iniciativas ou propostas de ação concertadas com outras áreas de política social.

\section{Inclusão da intersetorialidade nos princípios e nos programas do Sistema Único de Saúde: dilemas e perspectivas}

Do ponto de vista da saúde, área que historicamente apresenta maior acúmulo em termos da experiência política, durante todo o período recente de consolidação institucional do SUS, não foi dado prioridade à implementação de estratégias de construção de um sistema de seguridade social, o que poderia ter ocorrido, mediado pela diretriz da intersetorialidade, presente no ideário da reforma sanitária. O fato é que a descentralização da saúde avança em termos do planejamento e gestão setorial, mas, na atualidade, observa-se que tais conquistas são limitadas pela persistência do modo fragmentado de produzir a política saúde no país.

A área da saúde incorporou a diretriz da intersetorialidade em sua lei orgânica de 1990. Tal diretriz aparece como uma das dimensões que prevêem, na sua concepção, a integração intrasetorial da rede assistencial com a intersetorial, ou seja, a 
ação articulada com outras áreas de política social para produzir melhores resultados de saúde.

Pesquisas recentes mostram que a noção de integralidade apresenta caráter bastante difuso, tanto para os gestores quanto para profissionais de saúde. Além disso, a integralidade não assume na agenda setorial a conotação de prioridade. Autores como Giovannella et al. (2002) e Mattos (2001) apontam que a integralidade é a diretriz do SUS que menos se desenvolveu nestes 20 anos de existência do sistema, ao contrário das diretrizes da descentralização e do controle social, tomadas como centrais na trajetória recente do setor.

Assim, a articulação da saúde com outros setores de política social não tem sido a perspectiva predominante adotada pelos gestores dos três níveis de governo responsáveis pela execução da política de saúde. De fato, as estratégias implantadas com vistas à consecução do princípio da integralidade apontam para a priorização da articulação entre diferentes níveis de atenção à saúde (básica, média e alta complexidade) dentro do sistema municipal, com incentivo à regionalização dos serviços via criação de consórcios intermunicipais, ainda que o problema da integração interna do sistema permaneça como desafio para o SUS.

Embora a integralidade venha ganhando relevância na agenda setorial nos últimos anos a partir do reconhecimento das lacunas advindas de sua não priorização ao longo da implementação do SUS, sua operacionalização até o momento tem se mostrado insuficiente para contribuir de maneira efetiva para fomento de mudanças no quadro atual de organização fragmentada das políticas sociais brasileiras.

Entretanto, a preocupação com a necessária interface da política de saúde com outros setores pode ser observada também na retomada de questões que foram, nos últimos anos, relegadas ao segundo plano. É o caso, por exemplo, do debate sobre os determinantes sociais do processo saúde-doença ${ }^{4}$ e o retorno à concepção original de reforma sanitária. A atual retomada destes temas parece indicar a intenção de recuperar a potência política da reforma setorial ${ }^{5}$, e, ao mesmo, tempo buscar saídas para os impasses atuais. Nestas circunstâncias, a intersetorialidade tem sido pensada como uma estratégia fundamental para atuar sobre problemas estruturais da sociedade e que incidem sobre o processo saúde-doença. Em virtude disso, movimentos internacionais como a Promoção da Saúde, Cidades Saudáveis e Políticas Públicas Saudáveis, cuja lógica incorpora necessariamente ações intersetoriais, vêm ganhando centralidade no âmbito do setor saúde no país.

Os autores são unânimes em apontar que a atuação, a partir das múltiplas e complexas determinações do processo saúde-doença que se inserem nas formulações recentes, agrupadas sob o conceito de promo- ção da saúde, é de fato promissora, mas também desafiadora e complexa, tanto do ponto de vista político quanto técnico (TEIXEIRA; PAIM, 2000, CAMPOS, 2003). Isso se dá em função da própria marca histórica inscrita na política de saúde brasileira e sua persistente ineficácia frente a um conjunto significativo de agravos. Além disso, também porque muitas das ações necessárias para a promoção da saúde envolvem instâncias que se encontram fora do setor saúde. A promoção da saúde implica, necessariamente, no estabelecimento de agendas públicas com a participação de diversos atores para se alcançar mais saúde e uma melhor qualidade de vida (CAMPOS, 2003).

Outra iniciativa extremamente relevante, que traz para o campo da saúde a necessidade da pactuação intersetorial, são as experiências de programas prioritários do Ministério da Saúde - como o Programa de Saúde da Família (PSF) e o Programa de Agentes Comunitários de Saúde (ACS's) - desenvolvidas desde meados dos anos 1990 e concebidas como estratégias estruturantes da atenção básica em saúde e como porta de entrada do SUS. Segundo o próprio Ministério da Saúde, a equipe de saúde da família tem como uma de suas atribuições atuar de forma intersetorial, por meio de parcerias estabelecidas com diferentes segmentos sociais e institucionais, de forma a intervir em situações que transcendem a especificidade do setor saúde, com efeitos determinantes sobre as condições de vida e saúde dos indivíduos, famílias e comunidade.

Em que pese o empenho do Ministério da Saúde, em termos da priorização da atenção básica e da inequívoca expansão da Estratégia de Saúde da Família $^{6}$, são muitas as problemáticas a enfrentar para a mudança efetiva do modelo assistencial e para a promoção de melhores níveis de saúde no país.

Um dos principais desafios colocados à efetivação do modelo de atenção à saúde da família, tal como preconizado na legislação setorial, é a persistência da concepção endógena prevalente no campo da saúde e que se expressa na prática de seus profissionais. Importante lembrar que o Programa de Saúde da Família está sendo implementado, via de regra, nas áreas mais periféricas, onde a pobreza e suas multicausalidades apresentam sua face mais aguda, tornando óbvias as "incompletudes" do setor saúde para impactar os indicadores locais com intervenções isoladas.

As dificuldades de fixar médicos na equipe multiprofissional de saúde da família tem sido um desafio em todo o território nacional e não se coloca apenas como um problema de mercado de trabalho. Isso reflete, entre outras coisas, a persistência do paradigma biológico ainda hegemônico no campo da saúde, o que dificulta inclusive a percepção da insuficiência das ações de saúde frente aos agravos presentes e o seu corolário que seria a busca de parcerias intersetoriais. 
Ressalte-se que a concepção da saúde da família prevê a extensão da intervenção sanitária para além da consulta estrito senso, sendo necessárias, para impactar os indicadores de saúde das comunidades atendidas, as ações de educação e saúde como prática cotidiana, sob pena de se reproduzir o modelo de atenção tradicional.

Merhy (1997) ilumina este ponto ao sustentar que as diretrizes que presidem o fazer médico orientamse para a produção de procedimentos que alimentam o exercício do trabalho clínico, totalmente voltado para os interesses privados, estranhos aos dos usuários, e isolado de uma atuação mais coletiva no interior das equipes de saúde. $\mathrm{O}$ autor acrescenta ainda que este modelo de trabalho médico resiste, fechado e protegido no espaço físico do consultório, em nome de uma eficácia e de uma ética que não se sustentam em nenhum indicador de saúde.

A área de saúde, na sua busca por resultados mais efetivos através da transversalidade de ações no campo social, mantém ainda uma visão voltada para seu objeto de intervenção específico. Nesta perspectiva, o que prevalece no campo da saúde coletiva, incluindo aí a definição da própria Organização Mundial da Saúde (OMS), é a ideia de ação intersetorial como articulação de vários setores para alcançar melhores resultados de saúde (melhorar taxas de mortalidade infantil, hipertensão, desnutrição, por exemplo). Isto pode ser constatado na própria concepção de intersetorialidade que vem orientando estas iniciativas, como demonstram as definições que seguem:

Ações intersetoriais em saúde correspondem a uma relação reconhecida entre uma ou várias partes do setor saúde com uma ou várias partes de outro setor que se tenha formado para atuar em um tema visando a alcançar resultados de saúde (ou resultados intermediários de saúde) de uma maneira mais efetiva, eficiente ou sustentável do que poderia alcançar o setor saúde agindo por si só (OMS, 1997 apud TEIXEIRA; PAIM, 2000, p. 64).

Uma intervenção coordenada de instituições em ações destinadas a abordar um problema vinculado à saúde (SUÁREZ,1992 apud FERREIRA; SILVA, 2005, p. 103).

O debate dentro da própria área de saúde reconhece esta endogenia. Nesse sentido, ainda que não desconhecendo a forte liderança do setor saúde na proposição de ações intersetoriais, via projetos no campo da Promoção da Saúde, a Organização Panamericana de Saúde (OPAS) sinaliza que a ação intersetorial demanda da área de saúde não somente iniciativa, mas receptividade a convocatórias de outros setores (COSTA, 2006).

Sabe-se que a ação intersetorial traz como imperativo a construção de objetos de intervenção comum (ANDRADE, 2006) entre diferentes setores com vistas à consecução de planejamento integrado para enfrentamento dos problemas prioritários identificados. Contudo, a literatura especializada vem demonstrando que na prática isto suscita altos níveis de conflito e disputa política entre as diferentes áreas e atores envolvidos no processo. Além da competição em torno das estruturas de poder, também se percebem as disputas corporativas que permeiam o aparelho de Estado. Nesse requisito, Ferreira e Silva (2005) sinalizam que, enquanto a realidade opera com problemas complexos e mal-estruturados, as instituições organizam-se em setores e as universidades fragmentam o saber em departamentos.

\section{Trajetória recente da política de assistência social e concertação intersetorial}

No que concerne à política de assistência social, as mudanças preconizadas na Carta de 1988 não foram capazes de alterar os históricos problemas de fragmentação e descoordenação que tradicionalmente se apresentam neste campo. A Lei Orgânica da Assistência Social (LOAS), promulgada em dezembro de 1993 (BRASIL, 1993), permaneceu por mais de uma década como uma "carta de intenções" e menos como um instrumento capaz de gerar alterações eficazes na organização da prestação de serviços assistenciais ${ }^{7}$.

De acordo com a LOAS, a assistência social é direito do cidadão e dever do Estado; é política de seguridade social não contributiva que prevê os mínimos sociais, realizada através de um conjunto integrado de iniciativas públicas e da sociedade para garantir o atendimento às necessidades básicas.

Apesar dos obstáculos à sua implantação, a LOAS inaugurou um novo debate político-institucional no campo da assistência, propondo mudanças estruturais e conceituais e novas relações interinstitucionais e intergovernamentais, confirmando-se enquanto possibilidade de reconhecimento público da legitimidade das demandas de seus usuários. A população em situação de pobreza deixou de ser "assistida" ou "favorecida" para se tornar usuária ou beneficiária.

O tema da pobreza e a discussão em torno das ações governamentais necessárias para fazer face às históricas desigualdades sociais passam a ocupar lugar de destaque na agenda pública do governo eleito em 2003. A elevação desta problemática ao rol das prioridades governamentais empresta, sem dúvida, um novo sentido ao campo da assistência social como política pública.

Apesar de sua regulamentação ${ }^{8}$, a LOAS avançou muito pouco no sentido de conferir uma nova institucionalidade à política de assistência social, e é somente na IV Conferência Nacional de Assistência 
Social, realizada em dezembro de 2003, que se define uma nova agenda com diretrizes objetivas em relação à organização desta arena setorial. Pode-se afirmar que, a partir deste momento, em condições políticas e econômicas favoráveis, a intersetorialidade passa a ser a tônica dos debates no campo da assistência social, muito embora, desde os anos 1990, diversos estudiosos da área já proclamassem que "políticas e programas articulados representam, sem dúvida, um salto qualitativo na intervenção pública" (SPOSATI; YAZBEK, 1990).

No ano de 2004, é criado o Ministério do Desenvolvimento Social (MDS) que tem investido na (re)construção da política de assistência social com base, sobretudo, na formulação de programas com desenho intersetorial. A criação do MDS confere um novo estatuto à política de assistência, com reforço da perspectiva de profissionalização da área. Isso significa que, pela primeira vez na história da constituição da seguridade no país, há um movimento concreto para romper com o legado clientelista e assistencialista que marca esta área.

Ainda em 2004, o MDS tornou pública a versão final da Política Nacional de Assistência Social (PNAS), onde se destaca a criação do Sistema Único de Assistência Social (SUAS). A PNAS (BRASIL, 2004) apresenta a intersetorialidade como requisito fundamental para garantia dos direitos de cidadania, e, para efeito da operacionalização do SUAS, está previsto que as ações no campo da assistência social devem ocorrer em sintonia e articulação com outras políticas públicas.

O SUAS tem como principais pressupostos a territorialidade, a descentralização e a intersetorialidade. Entende-se que o paradigma desse sistema articula a descentralização com a intersetorialidade, uma vez que o objetivo visado é promover a inclusão social ou melhorar a qualidade de vida, resolvendo os problemas concretos que incidem sobre a população de um dado território (SIMÕES, 2009).

Para Pereira (2007), o SUAS é, nos termos da lei, um mecanismo organizador dos preceitos, disposições, ações e procedimentos previstos na LOAS e na PNAS, garantindo, do ponto de vista operacional e em caráter sistêmico (funcionalmente interligados), a implementação e a gestão da política.

Os principais objetivos do SUAS são a garantia da proteção social como forma de conquista da autonomia, do acesso a serviços e benefícios, da sustentabilidade e do protagonismo de cada cidadão. Para tanto, estabelece cinco princípios referentes a essa proteção: matricialidade sociofamiliar, territorialização, proteção proativa, integração à Seguridade Social e a integração das políticas sociais e econômicas ${ }^{9}$.

Ademais, o SUAS prevê uma estrutura unificada com partilha de responsabilidades entre os entes federados e as instâncias do sistema descentralizado e participativo, institui atividades de informação, monitoramento e avaliação, assim como preconiza uma lógica orçamentária que garante co-financiamento com repasse automático de recursos. Nesses termos, o SUAS tende a representar uma nova concepção de organização e gestão dos serviços, cuja construção contou com a participação ativa dos técnicos da área.

Observa-se que um dos programas centrais do MDS, o Programa Bolsa Família (PBF), traz expressa a preocupação em dar um passo adiante no enfrentamento da fragmentação da intervenção do Estado na área social. Isso porque, além da descentralização e do controle social, o desenho do PBF é fortemente pautado na intersetorialidade. Até hoje nenhum outro programa social foi tão dependente da articulação intersetorial e, portanto, das capacidades institucionais e de diálogo político entre os entes da federação e os diferentes setores responsáveis pelo desenvolvimento das políticas sociais ${ }^{10}$.

Embora a assistência social, dentre as áreas que compõem o tripé da Seguridade Social, seja a que tenha maior clareza política acerca da importância de se estabelecer estratégias de atuação intersetorial (e isto está presente nos documentos oficiais e no desenho da própria política), a capacidade institucional, financeira e política desta arena setorial ainda é muito baixa. Tal circunstância se evidencia na dificuldade de muitos municípios, inclusive aqueles com experiências exitosas em outras áreas de política social, de implantar as unidades de atenção básica e especial da assistência social, como o Centro de Referência de Assistência Social (CRAS) e o Centro de Referência Especializado de Assistência Social (CREAS) ${ }^{11}$. Essas são estruturas mínimas e fundamentais para corporificar a prestação de serviços da política de assistência social no âmbito local.

Acompanha esta tradição de frágil institucionalização a frequente ausência de um corpo técnico concursado, fazendo com que os programas e projetos venham historicamente sendo desenvolvidos por profissionais contratados de forma temporária, o que dificulta a sedimentação de uma memória técnica setorial, além dos problemas relativos à interveniência do clientelismo político na área, ainda persistente no nível local. Em razão disto, tem-se dificuldade em relação à continuidade e à sustentabilidade das experiências de implementação de programas e ações no campo da assistência social. As raízes disso estão na histórica falta de profissionalização da área de assistência social, na sua trajetória assistencialista, edificada na filantropia e na ausência de direitos, com fraca presença do Estado.

Esse legado histórico de não conformação da assistência social como política pública abre espaço para a baixa prioridade dada pelos governos à área em seus respectivos orçamentos, onde os contingen- 
ciamentos de recursos são praxe, principalmente, em períodos eleitorais. Uma explicação para este baixo grau de compromisso dos governos com a prestação de serviços assistenciais pode ser buscada, entre outras, na própria natureza da clientela da assistência social, ou seja, cidadãos marginalizados da esfera econômica que também não se fazem representar no campo da política.

Contudo, embora não se possa desconhecer o peso deste legado, o cenário que se descortina hoje no campo da política de assistência é propício à alteração deste padrão e aponta na direção da tentativa de conferir um estatuto de política pública à assistência social no país.

No contexto de montagem do novo arcabouço institucional na área, as discussões sobre os desafios de implementação da intersetorialidade constituem certamente elemento central. Isto se dá em função do próprio objeto de intervenção para o qual a assistência social se volta: indivíduos e famílias em situação de vulnerabilidade social, onde, em muitos casos, os laços familiares e sociais já estão rompidos. Para intervir com algum grau de eficácia diante deste estado avançado de "desfiliação" (no sentido em que lhe empresta Castel, 1998) em que se encontra parte significativa de sua clientela, é exigida da assistência social uma posição proativa na busca de ação coordenada entre diferentes setores do Estado. Em outras palavras, o próprio objeto de intervenção da assistência social, marcado por demandas multifacetadas, exige respostas que extrapolam a repartição setorial.

\section{Considerações finais}

Buscou-se aqui argumentar que, embora a passos lentos, alguns movimentos permitem identificar o potencial para retomada do debate em torno da Seguridade Social. Destaca-se nesse cenário o paradigma da promoção da saúde e a reatualização da discussão sobre os determinantes sociais nessa área que se refletem em programas prioritários fortemente dependentes da ação intersetorial. No campo da assistência social, as iniciativas de interface com outros setores constituem peça chave na pró- pria regulamentação do Ministério do Desenvolvimento Social e em seus principais programas.

Diante de um legado em que os setores que compõem a Seguridade Social apresentam trajetórias e memórias técnicas diferentes, o desafio atual é criar formas e mecanismos inovadores que favoreçam a reconstrução do sistema de Seguridade Social, buscando resgatar o sentido de integração e transversalidade presente na ideia de sistemas e redes de proteção social.

No âmbito desta discussão, é fundamental chamar atenção para outros desafios que interferem no sucesso da concertação intersetorial. Sobre isto, há um consenso de que a incorporação, por parte da saúde, da estratégia da intersetorialidade rumo à construção de objetivos comuns em conjunto com outros setores sociais envolve, necessariamente, a mudança do paradigma biológico que persiste na área (ANDRADE, 2006; COSTA, 2006).

Sobre os desafios de implantação do SUAS, sua operacionalização vem esbarrando em fortes debilidades referentes à estruturação de infraestrutura e de constituição do quadro de recursos humanos. Tal quadro, decerto, conforma um tipo de fragilidade político-institucional favorável à permeabilidade de interesses políticos eleitoreiros nos processos locais de implementação dessa política (MONNERAT; SOUZA, 2008). Entretanto, como foi visto, o cenário contemporâneo abre um campo de possibilidades de diálogo intersetorial, não só entre estas duas arenas, mas também entre outras áreas de política social.

Com efeito, tanto no que toca à Seguridade Social quanto à intersetorialidade pode-se afirmar que ambas se confrontam com a complexidade dos problemas sociais atuais. Nesta linha de raciocínio, os desenhos dos programas sociais, condizentes com o princípio da seguridade e com a perspectiva intersetorial, requerem, necessariamente, a ação coordenada das três esferas governamentais e dos diversos setores de um mesmo nível de governo, além de participação e controle sociais. Esse processo é altamente complexo porque não pode dispensar o envolvimento de um número muito elevado de atores, além de exigir uma estrutura política e institucional que favoreça a cooperação e o compartilhamento de 
objetivos. Impõem-se, portanto, inovações do ponto de vista das práticas desenvolvidas intra e extrassetorialmente.

\section{Referências}

ANDRADE, L. O. M. de. A saúde e o dilema da intersetorialidade. São Paulo: Hucitec, 2006.

BRASIL.Constituição da República Federativa do Brasil: promulgada em 5 de outubro de 1988. São Paulo: Saraiva, 2002.

. Ministério da Previdência Social. Lei n. 8.742, de 7 de dezembro de 1993. Dispõe Sobre a Organização da Assistência Social e dá outras providências. Brasília, 1993.

Ministério do Desenvolvimento Social e Combate à Fome e a Miséria. Política Nacional de Assistência Social (PNAS). Brasília, 2004.

CAMPOS, C. E. A. O desafio da integralidade segundo as perspectivas da vigilância da saúde e da saúde da família. Ciencia e Saúde Coletiva, v. 8, n. 2, p. 569-584, 2003.

CASTEL, R. As metamorfoses da questão social: uma crônica do salário. Petrópolis: Vozes, 1998.

COSTA, A. M.; PONTES, A. C. R.; ROCHA, D. G. Intersetorialidade na produção e promoção da saúde. In: CASTRO, A.; MALO, M. (Org.). SUS: ressignificando a promoção da saúde. São Paulo: Hucitec, 2006, p. 96-115.

FERREIRA, V. S. C.; SILVA, L. M. V. Intersetorialidade em saúde: um estudo de caso. In: HARTZ, Z. M. A.; SILVA, L. M. V. (Org.). Avaliação em saúde: dos modelos teóricos à prática na avaliação de programas e sistemas de saúde. Rio de Janeiro: Fiocruz, 2005, p.103-150.

FLEURY, S. A Seguridade Social inconclusa. 2006. Disponível em: 〈www.fgv.rj.br〉. Acesso em: 6 jul. 2008.

GIOVANELLA, L. et al. Sistemas municipais de saúde e a diretriz da integralidade da atenção: critérios para avaliação. Saúde em Debate, Rio de Janeiro, v. 26, n. 60, p. 37-61, 2002.

MATTOS, R. Os sentidos da integralidade: algumas reflexões acerca de valores que merecem ser defendidos. In: PINHEIRO, R.; MATTOS, R. (Org.). Os sentidos da integralidade na atenção e no cuidado à saúde. Rio de Janeiro: IMS-UERJ/Abrasco, 2001.

MERHY, E. E. Em busca do tempo perdido: a micropolítica do trabalho vivo. In: MERHY. E. E.; ONOCKO, R. (Org.). Agir em saúde. São Paulo: Hucitec, 1997, p. 71-112.
MONNERAT, G. L.; SENNA, M. C. Seguridade Social no Brasil: dilemas e desafios. In: MOROSINI, M. V.; REIS, J. R. F. Sociedade, Estado e direito à saúde. Rio de Janeiro: EPSJV/Fiocruz, 2007.

.; SOUZA, R. G. Relatório de pesquisa Programa Bolsa Família: Percepções e Trajetórias de inserção das famílias beneficiárias no município de Niterói/RJ. Rio de Janeiro: Secretaria Municipal de Assistência Social UERJ/ FSS, 2008.

. A Assistência Social prevista na Constituição de 1988 e a operacionalizada pela PNAS e pelo SUAS. Ser Social, Brasília, n. 20, p. 9-32, jan./jun., 2007.

SIMÕES, C. Curso de Direito de Serviço Social. São Paulo: Cortez, 2009

SPOSATI, A.; YAZBEK, M. C. A Assistência Social na trajetória das políticas sociais. São Paulo: Cortez, 1990.

TEIXEIRA, C. F; PAIM, J. S. Planejamento e programação de ações intersetoriais para a promoção de saúde e da qualidade de vida. Revista de Administração Pública, Rio de Janeiro, v. 34, p. 63-80, 2000.

VIANNA, M. L. T. W. A americanização (perversa) da Seguridade Social no Brasil: estratégias de bem-estar e políticas públicas. Rio de Janeiro: Revan, 1998.

O silencioso desmonte da Seguridade Social no Brasil. In: BRAVO, M. I. S.; PEREIRA, P.A. P.(Org.). Política social e democracia. São Paulo: Cortez, 2001.

VIANNA, S. M. A Seguridade Social e o SUS: re-visitando o tema. Saúde e Sociedade, v. 14, n. 1, p. 7-22, jan./abr., 2005.

\section{Notas}

1 Ogoverno Collor (1990-1992) aprofunda o desenvolvimento de políticas neoliberais no país, acompanhadas de fortes contingenciamentos de gasto social e de privatizações.

2 Boa parte dos recursos que deveriam ser destinados à Seguridade Social é usada para custear gastos governamentais estranhos a ela.

3 APrevidência Social, única com função arrecadadora, buscou assegurar a maior parte dos recursos, reservando para si o montante oriundo das contribuições sobre salários. À saúde, cuja preocupação com a vinculação de recursos específicos para o setor remonta aos anos 1980, foram atribuídas as receitas das contribuições sobre o lucro (Finsocial) e, posteriormente, Contribuição sobre o Lucro Líquido das Empresas (CSLL). Abusca de vinculação de recursos para a 
saúde traduziu-se, posteriormente, na criação de uma fonte exclusiva para o setor, através da Contribuição Provisória sobre Movimentação Financeira(CPMF), extinta em 2008.

4 Recentemente o Ministério da Saúde implantou, de acordo com recomendação da Organização Mundial da Saúde, a Comissão Nacional sobre Determinantes Sociais da Saúde.

5 De certa forma, no período pós-constituinte, houve um privilegiamento do debate sobre as questões relacionadas à gestão da política de saúde.

6 Segundo dados do Ministério da Saúde de 2009, estão atuando no país em torno de 30 mil equipes de saúde da família, em 94\% dos municípios brasileiros, cobrindo 103 milhões de pessoas.

7 A exceção aqui recai sobre o Benefício de Prestação Continuada (BPC) que foi implementado ainda na década de 1990.

8 Isso ocorreu tardiamente em 1995, ao passo que a regulamentação do setor saúde deu-se em 1990.

9 A partir destes princípios, a proteção social é dividida em: básica (com caráter preventivo) e especial (com caráter reparador).

10 Para se manterem no Bolsa Família, as famílias beneficiárias devem cumprir as condicionalidades da educação e saúde, o que jáimpõe por si só um grau mínimo de integraçãoe diálogo entre as áreas envolvidas (assistência social, educação e saúde).

11 Tais dificuldades vêm sendo evidenciadas em estudos voltados para a análise de experiências municipais de implementação de programas da assistência social (MONNERAT;SOUZA, 2008)

\section{Giselle Lavinas Monnerat}

glmonnerat@yahoo.com.br

Doutora em Saúde Pública pela ENSP/Fiocruz

Professora adjunta da Faculdade de Serviço Social da Universidade do Estado do Rio de Janeiro (UERJ)

\section{Rosimary Gonçalves de Souza}

rgdsouza@uol.com.br

Doutora em Saúde Pública pela ENSP/Fiocruz

Professora adjunta da Faculdade de Serviço Social da UERJ

\section{UERJ - Faculdade de Serviço Social}

Rua São Francisco Xavier, 524

Maracanã
Rio de Janeiro - Rio de Janeiro

CEP: 20550-011 